\title{
The role of plastic and reconstructive surgeon in trauma care: Perspectives from a Level 1 trauma centre in India
}

\author{
Maneesh Singhal, Ravikiran Naalla, Aniket Dave, Moumita De, Deepti Gupta, Shashank Chauhan \\ Department of Plastic Reconstructive and Burns Surgery, All India Institute of Medical Sciences, New Delhi, India \\ Address for correspondence: Prof. Maneesh Singhal, Department of Plastic Reconstructive and Burns Surgery, Plastic Surgery Office, \\ $5^{\text {th }}$ Floor, Teaching Block, All India Institute of Medical Sciences, New Delhi, India. E-mail: drmaneesh@gmail.com
}

\begin{abstract}
Background: As the morbidity and mortality due to trauma are ever increasing, there is proportionally growing need of trauma care facilities across the country. In the context of expanding designated trauma care facilities, the role of plastic and reconstructive surgeon needs to be analysed and defined at least at a Level 1 trauma centre. Materials and Methods: We included the patients who were operated under the department of plastic, reconstructive \& burns surgery at a Level 1 urban trauma centre between January 2016 and December 2017. We analysed the demographic data and categorised operative data according to anatomical areas and interacting specialties. Results: A total of 1539 procedures were performed under the division of plastic reconstructive and burn surgery. Amongst them, $81 \%$ were male, and $19 \%$ were female. Mean age was 27.3 years (range: $3-90$ years). The anatomical locations treated were upper limb $(49 \%)$, lower limb (35\%), head and neck (8\%) and trunk (8\%). Interdepartmental cases were 600 and majority of them were in collaboration with orthopaedics $(n=298)$, general surgery $(n=163)$, neurosurgery (79) and maxillofacial surgery (60). Conclusion: There is a significant role of plastic surgeon at a Level 1 trauma centre in India. The plastic surgeon's interventions are limb saving and sometimes lifesaving, many at times morbidity of post-traumatic sequelae are either prevented or treated. Along with other core specialties involved in the management of trauma, plastic surgeons play an integral role in a Level 1 trauma centre. The policymakers should take note to augment the number of plastic surgeons at a Level 1 apex trauma centre on par with other specialties, as the workload is heavy and is steadily on an increasing trend.
\end{abstract}

\section{KEY WORDS}

Level 1 trauma centre; reconstructive surgery; trauma reconstruction

\begin{tabular}{|l|l|}
\hline \multicolumn{2}{|c|}{ Access this article online } \\
\hline Quick Response Code: & Website: \\
\hline & www.ijps.org \\
\cline { 2 - 2 } & Dol: \\
\hline
\end{tabular}

This is an open access journal, and articles are distributed under the terms of the Creative Commons Attribution-NonCommercial-ShareAlike 4.0 License, which allows others to remix, tweak, and build upon the work non-commercially, as long as appropriate credit is given and the new creations are licensed under the identical terms.

For reprints contact: reprints@medknow.com

How to cite this article: Singhal M, Naalla R, Dave A, Moumita De, Gupta D, Chauhan S. The role of plastic and reconstructive surgeon in trauma care: Perspectives from a Level 1 trauma centre in India. Indian J Plast Surg 2018;51:170-6. 


\section{INTRODUCTION}

ccording to the Ministry of Road Transport and Highways, Government of India annual publication, 'Road Accidents in India-2016' over 1.5 lakhs deaths were noted in the year 2016. ${ }^{[1]}$ The unreported morbidity of post-traumatic sequelae is expected to be much higher. Apart from the management of life-threatening visceral injuries, a high-volume Level 1 trauma centre is faced with challenges about management of soft-tissue injuries of extremities, trunk, complex maxillofacial injuries and their sequelae.

The need of plastic surgeon at a Level 1 trauma centre is undeniable. ${ }^{[2]}$ Although the literature search reveals significant work of several authors in the field of extremity ${ }^{[3,4]}$ and craniofacial ${ }^{[5]}$ trauma, the holistic role of plastic and reconstructive surgeon in the multidisciplinary trauma management has never been reported from India. Such data help in training of residents of plastic surgery and other specialties for better understanding the concept of interdisciplinary management and delivery of quality healthcare to victims of trauma. In the context of upcoming expansion of Level 1 trauma centres and other designated trauma care facilities across the country, a study with this background may be useful for policymaking, planning and financing, the establishment of minimum standards for the performance of a trauma care system.

The study was aimed to report the role and quantify the operative workload of plastic surgeon at a Level 1 trauma centre with an emphasis on interdisciplinary management and formulate recommendations based on our experience.

\section{MATERIALS AND METHODS}

We reviewed the prospectively collected data of the patients who underwent treatment by the department of plastic reconstructive and burns surgery at a Level 1 trauma centre from January 2016 to December 2017. The demographic data were analysed, anatomical categorisation was made, and the interdisciplinary role of a plastic surgeon with other specialties was defined.

\section{RESULTS}

Atotal of 1539 procedureswere performed in 1095 patients by the department of plastic, reconstructive and burns surgery. A total of 939 procedures were performed on patients admitted under our department and 600 procedures were performed by us as part of cross-referral on patients admitted under other specialties. Out of the 1095 patients, 621 were admitted under our department, whereas 474 were admitted under other specialties at the trauma centre. Amongst them, $81 \%$ were male and $19 \%$ were female. Mean age was 27.3 years (range: 3-90 years). The anatomical locations treated were upper limb (49\%), lower limb (35\%), head and neck (8\%) and trunk (8\%). The spectrum of cases and detailed classification of the cases dealt at a Level 1 trauma centre by a plastic surgeon at the time of publication are tabulated [Tables 1-4]. The 600 interdepartmental cases were performed as a part of cross-referral. Majority of them were in collaboration with orthopaedics $(n=298)$, general surgery $(n=163)$, neurosurgery $(n=79)$ and maxillofacial surgery $(n=60)$. Combined plastic surgery, orthopaedic and general surgery intervention was required in 60 patients, and all the above-mentioned specialities were involved in 20 patients. Majority of the interdepartmental surgeries with orthopaedics were related to extremity soft-tissue cover. With general surgery, skin grafting was the most common surgery. Interdepartmental cases with neurosurgery were mostly related to head-and-neck procedures, and with maxillofacial surgery, plastic

Table 1: Classification of head and neck procedures

\begin{tabular}{lc}
\hline $\begin{array}{l}\text { Procedures according to anatomical } \\
\text { location }\end{array}$ & Number of patients \\
\hline Scalp reconstruction & \\
Laceration repair & 14 \\
Local flap & 10 \\
Free flap & 1 \\
Revascularization & 2 \\
Replantation & 3 \\
Tissue expansion & 3 \\
Ear reconstruction & \\
Laceration repair & 18 \\
Local flap & 5 \\
With costal cartilage & 3 \\
Face reconstruction & \\
Laceration repair & 10 \\
Local flaps & 7 \\
Regional flaps & 8 \\
Free flaps & 1 \\
Tissue expansion & 4 \\
Rhinoplasty & 2 \\
Osteosynthesis (facial bones) & \\
Mandible reconstruction & \\
Midface reconstruction & 20 \\
Post-burn contracture release & 124 \\
Total &
\end{tabular}

Indian Journal of Plastic Surgery Volume 51 Issue 2 May-August 2018 
Table 2: Classification of trunk procedures

\begin{tabular}{lc}
\hline Procedures according to anatomical location & $\begin{array}{c}\text { Number of } \\
\text { patients }\end{array}$ \\
\hline Chest & 20 \\
Debridement & 5 \\
Skin grafting & 8 \\
Local myocutaneous/muscle flaps (open thoracic & \\
wounds) & 10 \\
NPWT & \\
Abdomen & 17 \\
Skin grafting & 2 \\
Component separation technique & 10 \\
NPWT & \\
Back & 8 \\
Debridement & 7 \\
Skin grafting & 15 \\
Local flap (pressure ulcer) & 8 \\
Local skin and muscle flaps (spinal implant & \\
exposure) & 13 \\
NPWT & 123 \\
Total &
\end{tabular}

NPWT: Negative pressure wound therapy

surgery assistance was most commonly required for providing soft-tissue cover after open reduction and internal fixation (ORIF). The interdepartmental patients were primarily admitted under and managed by the concerned speciality. Plastic surgery interventions in interdepartmental cases were concerned with either the same system/region managed by the respective specialties or different organ systems/regions. For example, the collaboration with maxillofacial surgery often involved flap cover following ORIF of facial fractures. However, it could also be in the form of K-wire fixation of coexisting of phalangeal fractures. Combinations of this kind are common because many of the patients present to us with multiple organ system injuries.

A total of 438 pedicled flaps were done, which included local/regional fasciocutaneous flaps, muscle flaps, musculocutaneous flaps and distant flaps. Majority of the flaps were performed for soft-tissue cover in the extremities (221 for upper limb and 137 for lower limb). The most commonly performed flaps for upper extremity reconstructions included groin flap, thoracoumbilical flap and hypogastric flap. The most commonly performed pedicled flaps for lower extremity reconstruction were local random pattern fasciocutaneous flaps, reverse sural artery flap, gastrocnemius muscle flap and soleus/hemisoleus muscle flap. Flap reconstruction for trunk defects was done in 31 cases, and for head and neck, it was done in 30 cases. Common flaps for trunk reconstruction included latissimus dorsi myocutaneous flap, pectoralis major muscle/myocutaneous flap, Indian Journal of Plastic Surgery Volume 51 Issue 2 May-August 2018 rectus abdominis muscle flap and gluteus maximus myocutaneous flap (for pressure sores). Finally, nasolabial flap, forehead flap and deltopectoral flap were most commonly performed for head-and-neck reconstruction. Less commonly performed were pedicled anterolateral thigh flap, trapezius myocutaneous flap, posterior interosseous artery flap, pedicled radial forearm flap, medial plantar flap and cross leg flap.

A total of 29 free flaps were performed in this period by our department. These included 2 in head and neck, 3 in upper limbs and 24 in lower limbs. Amongst these, flap compromise was detected in seven patients, 5 (17.2\%) of which could not be salvaged even after re-operation. Forty-nine upper extremity replantations were performed at our centre. The level-wise distribution of these is mentioned in Table 3. Thirty-one (63.3\%) of these were successful. Eighteen (36.7\%) failed replantations included 15 in the hand and 1 each at the wrist, forearm and elbow.

\section{DISCUSSION}

A trauma care facility (trauma centre) is a healthcare institution that has the capabilities and resources necessary to provide appropriate trauma care services at a particular level to the injured patients. Trauma centre designation criteria set strict requirements for staffing, response times, training, specialist availability, community education and quality improvement. Trauma centres have been categorised into four levels: ${ }^{[6]}$

Level I Trauma centre provides the highest level of comprehensive and definitive care for patient with complex injuries. The multidisciplinary team in which the general surgeons, emergency medicine physicians, orthopaedic surgeons, neurosurgeons, intensivists, plastic surgeons and other allied surgical and non-surgical departments would be in-house and available to the trauma patient immediately on their arrival. Every department plays a crucial role in the functioning of the trauma center. ${ }^{[7]}$ All major super specialities associated with trauma care services would be available $24 \times 7$. Due to requirement of the specialists, infrastructure and high levels of skill, Level 1 trauma centres are only in medical college hospitals. In Level II trauma centres, the super speciality services are on call, Level III trauma centres are equipped to tackle patients who do not require specialised services and patients who required specialised care are referred to higher level centres. Level IV services are appropriately equipped and manned mobile ambulances/hospitals. 
Singhal, et al.: Plastic surgeon's role at level 1 trauma center

Table 3: Classification of upper extremity procedures

\begin{tabular}{|c|c|c|c|c|c|c|c|}
\hline & Procedures Hand & Wrist & Forearm & Elbow & Arm & Shoulder & Total \\
\hline \multicolumn{8}{|l|}{ Trauma reconstruction } \\
\hline Skin grafting & 10 & 6 & 25 & - & 5 & 2 & 48 \\
\hline Local flaps & 27 & - & 8 & 2 & 1 & - & 38 \\
\hline Regional flaps & - & 2 & 2 & 6 & - & - & 10 \\
\hline Distant flaps & 112 & 24 & 21 & 9 & 7 & - & 173 \\
\hline Free flaps & 1 & 1 & 1 & - & - & - & 3 \\
\hline Revascularization & $16^{*}$ & 1 & 3 & 2 & 2 & - & 24 \\
\hline Replantation & $41^{*}$ & 4 & 2 & 1 & 1 & - & 49 \\
\hline Amputation & 10 & 1 & 2 & 1 & 2 & - & 16 \\
\hline Debridement & 21 & 5 & 9 & 2 & 2 & - & 39 \\
\hline Lacerations & 15 & 5 & 6 & 1 & 1 & - & 28 \\
\hline Cut injuries $^{\dagger}$ & 28 & 61 & 15 & 4 & 3 & - & 111 \\
\hline Fracture fixation & 52 & - & - & - & - & - & 52 \\
\hline NPWT & 3 & - & 1 & - & - & - & 4 \\
\hline \multicolumn{8}{|l|}{ Tendon surgeries } \\
\hline Delayed tendon repair & 6 & 3 & 4 & - & - & - & 13 \\
\hline Tenolysis & 4 & 5 & 1 & - & - & - & 10 \\
\hline \multicolumn{8}{|l|}{ Post-burn reconstruction } \\
\hline Contracture release and skin grafting & 21 & 2 & - & 4 & - & 6 & 33 \\
\hline Contracture release and flap cover & 14 & 3 & - & 2 & - & - & 19 \\
\hline \multicolumn{8}{|l|}{ Brachial plexus } \\
\hline Primary reconstruction & 2 & & & & & & 2 \\
\hline Nerve transfers & & & & 6 & & 9 & 15 \\
\hline Secondary tendon transfer & - & - & - & 4 & - & 6 & 10 \\
\hline Functioning free muscle transfers & - & - & - & 6 & - & - & 6 \\
\hline Emergency repair ${ }^{\star}$ & 2 & & & & & & 2 \\
\hline \multicolumn{8}{|l|}{ Peripheral nerves } \\
\hline Delayed nerve repair & - & 8 & 4 & - & 2 & - & 14 \\
\hline Neurolysis & 7 & 5 & 2 & - & 1 & - & 15 \\
\hline Tendon transfers & - & 10 & - & - & - & - & 10 \\
\hline Escharotomy/fasciotomy & 10 & & & & & & 10 \\
\hline Total & 402 & 146 & 106 & 50 & 27 & 23 & 754 \\
\hline
\end{tabular}

Under the scheme of 'Capacity Building for Developing Trauma Care Facilities in Govt. Hospitals on National Highways', Ministry of Health and Family Welfare proposed the establishment of designated trauma care facilities at every $100 \mathrm{~km}$ on the highways and Level I trauma centre for every $750-800 \mathrm{~km} .{ }^{[6]}$ Upgrading and strengthening of existing medical college hospitals and centres into designated trauma centres is under active consideration according to the Ministry of Health and Family Welfare, Government of India. Patients with complex injuries which require higher level infrastructure and workforce are referred to the existing Level 1 trauma centres. Although the levels till date are not full-fledged, their upgradation is under process as per the ministry's latest report.

As of now, out of all the trauma care facilities, one plastic surgeon is allotted in a Level I trauma centre. Till date, our department is the first plastic surgery unit integrated into an established and fully functioning Level 1 trauma centre in India. Plastic, reconstructive and burns surgery department is new at our institute. In January 2016, we had two plastic surgery faculties and two residents. After that, two new residents joined us every 6 months and four consultants joined around December 2016. By December 2017, there were six consultants and eight senior residents in the department.

Initially, there was single plastic surgery faculty posted at the Level 1 trauma centre from our department, as the more faculty joined in the department they were posted in the trauma centre on rotation basis. During the period of study, two faculties and 3-4 residents were posted in the trauma centre on a full-time basis.

The integral role of plastic surgeon at a Level 1 trauma centre, ${ }^{[2,8,9]}$ and referral trauma centres ${ }^{[10,11]}$ have been 
reported by several authors across the world. The findings of predominantly male and younger population being affected by road traffic injuries are comparable with the other Level 1 trauma centres. ${ }^{[2,9]}$ These results are, however, different from other regional centres according to their demographic and social factors. ${ }^{[12,13]}$ The number of procedures, duration of study, most commonly operated region and interacted speciality are tabulated in Table 5 . The total number of procedures performed by us $(n=1539)$ in the time period are greater than those reported at other centres. Like most other Level 1 trauma centres, upper limb procedures comprise the largest chunk. Head-and-neck caseload is relatively less when compared to other series. With the available logistic support currently, approximately $10 \%$ of the cases done at Level 1 trauma centre are from plastic surgery department. In addition to direct referrals to the

Table 4: Classification of lower extremity procedures

\begin{tabular}{|c|c|c|c|c|c|}
\hline & $\begin{array}{l}\text { Procedures } \\
\text { Foot and } \\
\text { ankle }\end{array}$ & Leg & Knee & Thigh & Total \\
\hline \multicolumn{6}{|l|}{ Trauma reconstruction } \\
\hline Debridement & 18 & 38 & 13 & 16 & 85 \\
\hline Skin grafting & 56 & 63 & 15 & 51 & 185 \\
\hline \multicolumn{6}{|l|}{ Local flap } \\
\hline Fasciocutaneous & 27 & 34 & 10 & 1 & 72 \\
\hline Muscle flap & 1 & 41 & 15 & 2 & 59 \\
\hline Myocutaneous flap & - & 2 & 3 & 1 & 6 \\
\hline Free flaps & 11 & 13 & - & - & 24 \\
\hline Revascularization & - & 4 & - & 2 & 6 \\
\hline Replantation & - & - & - & - & \\
\hline Amputation & 2 & 4 & 1 & 1 & 8 \\
\hline Tendo-achilles repair & 4 & - & - & - & 4 \\
\hline \multicolumn{6}{|l|}{ Nerve reconstruction } \\
\hline Immediate & - & 11 & 1 & 2 & 14 \\
\hline Delayed & - & 4 & - & 2 & 6 \\
\hline Neurolysis & - & 3 & - & 4 & 7 \\
\hline Tendon transfer (foot drop) & 2 & - & - & - & 2 \\
\hline NPWT & 7 & 4 & 2 & 5 & 18 \\
\hline \multicolumn{6}{|l|}{ Post-burn reconstruction } \\
\hline $\begin{array}{l}\text { Contracture release and } \\
\text { skin grafting }\end{array}$ & 11 & 5 & 4 & 3 & 23 \\
\hline $\begin{array}{l}\text { Contracture release and } \\
\text { flap cover }\end{array}$ & 9 & 2 & 7 & 1 & 19 \\
\hline Total & 148 & 228 & 71 & 91 & 538 \\
\hline
\end{tabular}

Table 5: Comparison of our data with other major trauma centers across the world

\begin{tabular}{llccll}
\hline Author & Country & Procedures & Duration (years) & Distribution & Interacting specialty \\
\hline Oliveira et al..$^{[2]}$ & Portugal & 2496 & 5 & Hand $>$ head and neck & Ortho $>$ vascular surgery $>$ general surgery \\
Khan et al..$^{[10]}$ & Pakistan & 1013 (patients) & 3 & Hand $>$ head and neck & -NA- \\
Hendrickson et al. ${ }^{[11]}$ & UK & 132 & 1 & Lower limb $>$ hand & -NA- \\
Peterson et al. ${ }^{[9]}$ & USA & 1104 & 3 & Hand $>$ head and neck & Ortho $>$ general surgery $>$ Neuro \\
Our series & India & 1539 & 2 & Hand $>$ lower limb & Ortho $>$ general surgery $>$ Neuro \\
\hline
\end{tabular}

NA: Not available department from the distant places across the country, we also get referrals from other plastic surgery units in selected clinical scenarios like soft-tissue reconstruction in the setting of polytrauma, digital replantation \& hyperbaric oxygen therapy.

Pedicled flaps (local, regional or distant) are the mainstay of soft-tissue reconstruction at our centre, especially for extremity reconstructions. However, microsurgical reconstruction is also routinely performed whenever indicated. Free flaps are most commonly performed for lower limb defects due to the paucity of local/regional options. Upper extremity replantations are also routinely performed, with single finger replantation being the most common. All upper extremity amputations are considered for microvascular replantation unless contraindicated.

Although post-burn sequelae are managed routinely, the department is as of now is not managing acute burns on a regular basis. However, in the event of any burn disaster in the city there were few instances in which we treated acute burn patients. During this occasional incidents we have performed procedures like fasciotomy, escharotomy, early wound excision and skin grafting, allograft application, etc.

We believe that teamwork is the key to successful management of polytrauma victims and this in part is due to the round the clock availability of healthcare personnel from different specialities working for the best interests of patients. This is also reflected by the 600 interdepartmental cases which were operated by our department. Trauma training to plastic surgery residents involves exposure and insight into reconstruction from head to toe, comprising all ages and almost all organ systems. The training imparts skills in skin and soft tissue, tendon, nerve, vessel and bone reconstruction. This comprehensive preparation is vital in developing efficient younger generation plastic surgeons and residents from other specialities involved in trauma management too. The benefits are 
mutually exchanged, and resident in plastic surgery get to learn and implement the guidelines of advanced trauma life support, triage systems, resuscitation of victims with shock, etc., and necessary lifesaving skills such as airway, breathing and circulation stabilisation in the acute settings.

The Level 1 trauma centre usually provided its services for complex multisystem injuries including referral cases. Within the geographic area under its jurisdiction, the trauma centre is obliged to manage all the minor cases too. This additionally helps in resident training to impart skills in managing all types of injuries.

Although all of the mentioned patients do not require a Level 1 trauma centre care in a strict sense, the plastic surgeon at a Level 1 trauma centre has to deal with all the injuries which come under the scope of the speciality for the above-mentioned reasons. Patients with polytrauma are usually associated with minor to major limb-threatening injuries which requires plastic surgeon's expertise.

Apart from patients with multisystem injuries, extremity replantation and complex reconstructions, many of the soft-tissue injuries can be managed by a plastic surgeon if available at a level 2 trauma centre. If a plastic surgeon is not available, general surgeons should be trained in plastic surgery at a Level 2 trauma centre (existing medical colleges) for initial management and timely referral. Considering replantation as an emergency procedure, those cases have to be referred to higher centre appropriately. We do not recommend a plastic surgeon at a Level 3 as these centres are meant to stabilise and refer the patients to higher centres. In view of resources scarcity, usually patients who can be managed at a Level 2 trauma centre are already referred to other centres. Around $10 \%$ of our cases can be managed at a Level 2 trauma centre.

The burden at a level 1 trauma centre not only includes acute trauma but also the sequelae and further corrective surgeries associated with it. The advantage of the centre is that there is $24 \times 7$ availability of operation theatres and anaesthetists along with supporting staff dedicated to trauma care.

In addition to limb saving, the interventions of plastic surgeons reduce the morbidity and sometimes the mortality of the post-traumatic sequelae. We recommend that policymakers should take note to augment the number of plastic surgeons at a level one apex trauma centre on par with other specialties, as the work load is heavy and is steadily on an increasing trend. We recommend that general surgeons should be trained in plastic surgery at a level 2 trauma centre (existing medical colleges) for initial management and timely referral.

\section{CONCLUSION}

There is a significant role of plastic surgeon at a Level 1 trauma centre in India. The plastic surgeon's interventions are limb saving and sometimes lifesaving, many at times morbidity of post-traumatic sequelae are either prevented or treated. Along with other core specialties involved in the management of trauma, plastic surgeons play an integral role in a level 1 trauma centre. The policymakers should take note to augment the number of plastic surgeons at a level one apex trauma centre on par with other specialties, as the workload is heavy and is steadily on an increasing trend.

\section{Acknowledgement}

We thank all the faculty and residents of the department for their contribution to the clinical work.

\section{Financial support and sponsorship}

Nil.

\section{Conflicts of interest}

There are no conflicts of interest.

\section{REFERENCES}

1. Press Information Bureau Government of India Ministry of Road Transport \& Highways; 2016. Available from: http://www.pib.nic. in/newsite/PrintRelease. aspx?relid=170577. [Last accessed on 2017 Dec 19].

2. Oliveira I, Ferreira P, Barbosa R, Sanz E, Reis J, Amarante J. The plastic surgeon intervention at a level I trauma center. Eur J Plast Surg 2007;30:57-62.

3. Mahajan RK, Mittal S. Functional outcome of patients undergoing replantation of hand at wrist level-7 year experience. Indian J Plast Surg 2013;46:555-60.

4. Kadam D. Limb salvage surgery. Indian J Plast Surg 2013;46:265-74.

5. Singh AK, Mohapatra DP, Kumar V. Spectrum of primary bone grafting in Cranio maxillofacial trauma at a tertiary care centre in India. Indian J Plast Surg 2011;44:29-35.

6. Ministry of Health \& Family Welfare. Capacity building for developing trauma care facilities on national highways. Available from: http://www.dghs.gov.in/writereaddata/userfiles/ file/operational_guidelines_trauma.pdf. [Last accessed on 2017 Dec 19].

7. Thakar HJ, Pepe PE, Rohrich RJ. The role of the plastic surgeon in disaster relief. Plast Reconstr Surg 2009;124:975-81.

Indian Journal of Plastic Surgery Volume 51 Issue 2 May-August 2018 
8. Abdelhalim MA, Chatterjee JS. The operative trauma workload in a plastic surgery tertiary referral centre in Scotland. Eur J Plast Surg 2012;35:683-8.

9. Peterson SL, Moore EE. The integral role of the plastic surgeon at a level I trauma center. Plast Reconstr Surg 2003;112:1371-5.

10. Khan M, Aziz A, Naz S, Khan IM, Ullah A, Ullah H, et al. Plastic surgical trauma: A single-centre experience. Indian J Plast Surg 2012;45:538-45.

11. Hendrickson SA, Khan MA, Verjee LS, Rahman KM, Simmons J,
Hettiaratchy SP, et al. Plastic surgical operative workload in major trauma patients following establishment of the major trauma network in England: A retrospective cohort study. J Plast Reconstr Aesthet Surg 2016;69:881-7.

12. Kapoor P, Kalra N. A retrospective analysis of maxillofacial injuries in patients reporting to a tertiary care hospital in East Delhi. Int J Crit IIIn Inj Sci 2012;2:6-10.

13. Small TJ, Sheedy JM, Grabs AJ. Cost, demographics and injury profile of adult pedestrian trauma in inner Sydney. ANZ J Surg 2006;76:43-7. 